\title{
EUTOMIA
}

Revista de Literatura e Linguística

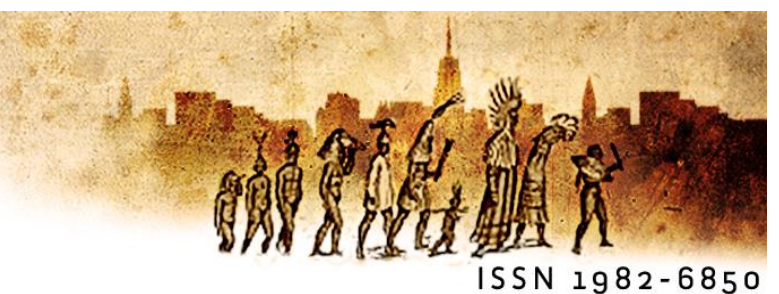

\section{Experiência Interior Subjetiva na Poesia de Eucanaã Ferraz}

\author{
João Felipe Gremski (UFPR)
}

Resumo: $O$ presente artigo busca estabelecer uma análise da obra de Eucanaã Ferraz, poeta carioca nascido em 1961, e com 6 livros publicados até o momento, partindo de características atribuídas tradicionalmente ao fazer poético de João Cabral de Melo Neto. O crítico Benedito Nunes comenta no seu livro, João Cabral: A Máquina do Poema (2007), o quanto a poesia de Cabral tenta suprimir a experiência interior subjetiva, entendida aqui como o fluxo de sentimentos que motivam a escrita de um poema, fazendo com que essa experiência se apresente apenas de forma fragmentária e residual nos versos. A partir dessa constatação, decidi verificar se isso ocorre na poesia de Eucanaã Ferraz e pude atestar que essa característica, ao contrário da poesia de Cabral, é mantida ao longo da sua obra; ao fazer isso, o sujeito poético atua com uma voz pessoal e, embora sob controle da sua matéria escrita, sentimental.

Palavras-chave: Eucanaã Ferraz, João Cabral de Melo Neto, experiência interior subjetiva.

Abstract: This article focuses on establishing an analisys of the poetic work of Eucanaã Ferraz, born in 1961 and with six books published, comparing his work with certain aspects of the poetry written by João Cabral de Melo Neto. The critic Benedito Nunes argues in his book, João Cabral: A Máquina do Poema (2007), how Cabral's poetry tries to suppress the internal subjective experience, understood here as a stream of sentiments that motivates the writing of a poem, turning this experience into mere residual fragments in the verses. From this line of thought, I decided to verify if this procedure occurs in Eucanaã's poetry, and I was able to attest that this specific characteristic, unlike Cabral's poetry, is mantained along his poetic work; by doing that, the poetic persona acts with a personal and sentimental voice.

Keywords: Eucanaã Ferraz, João Cabral de Melo Neto, internal subjective experience 


\section{Introdução}

João Cabral de Melo Neto e Eucanaã Ferraz são poetas de épocas distintas e com características que, acredito, possuam sim momentos de confluência, principalmente na maneira de trabalhar com imagens dentro do poema. Mas, ao olhar mais atentamente para cada uma das produções, fica claro que Eucanaã Ferraz, posterior ao poeta pernambucano e com ativa produção poética até os dias atuais, segue um caminho próprio tanto em termos estilísticos quanto temáticos.

Eucanaã Ferraz nasceu no Rio de Janeiro em 1961. É professor de literatura brasileira na UFRJ e autor de seis livros de poemas, entre eles Desassombro (2002), indicado ao Prêmio Portugal Telecom de Literatura Brasileira, Rua do Mundo (2004) e Cinemateca (2008). Publicou também livros infanto-juvenis e organizou antologias do poeta Vinícius de Morais. Considerado um dos grandes nomes da poesia brasileira contemporânea, sua obra é marcada tanto pela visualidade quanto pela clareza poética, aspectos que o aproximam de João Cabral, mas com um viés, como foi definido pelo próprio Eucanaã, trágico:

Assim, há tanto uma vontade de tornar claro quanto um desejo de conhecer o escuro. Essa luz de que tanto falam os meus poemas é da ordem da razão, sim, mas ela é também a imagem da compreensão de nossa condição trágica. (FERRAZ, apud PEDROSA, 2005, p. 89)

É essa dualidade claro-escuro que distinguirá a sua poesia da estética cabralina e será tratada mais adiante. Como escreve Eucanaã no seu segundo livro de poemas, Martelo:

\footnotetext{
O poema é ver com lanternas que cor é a cor do escuro.
}

(FERRAZ, 1997, p. 24) 
A poesia de João Cabral de Melo Neto é conhecida pela sua visualidade e por trabalhar com um vocabulário que, nas palavras de Benedito Nunes no seu livro João Cabral: A Máquina do Poema "despoja-se (...) de todas as roupagens supérfluas e de toda profundidade ilusória de todos os ornamentos da fantasia e da sublimação dos sentimentos." (NUNES, 2007, p. 45). Ou seja, João Cabral busca um distanciamento entre aquilo que considera afetivo e pessoal com a matéria da linguagem, procurando evitar que seus versos sejam "poetizados", como escreve em um dos poemas do livro Paisagem com Figuras:

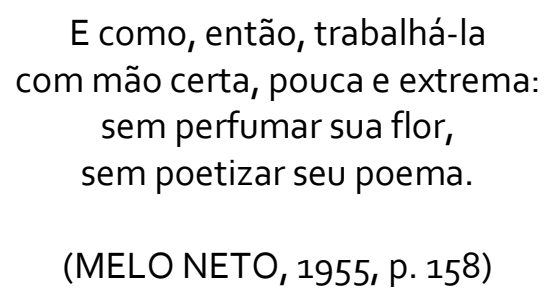

Tomando como base essa argumentação proposta por Benedito Nunes a respeito da poesia de João Cabral, será verificado na poesia de Eucanaã Ferraz se essa sensação causada por uma experiência interior é transposta para o poema ou se restam apenas resíduos de matéria morta, como disse Benedito Nunes a respeito da poética cabralina (NUNES, 2007, p. 30).

Para tanto, discorrerei brevemente sobre a questão da experiência subjetiva em João Cabral para, em seguida, buscar esse procedimento na obra de Eucanaã Ferraz.

\section{Experiência Interior Subjetiva}

\section{João Cabral de Melo Neto}

Como foi mencionado anteriormente, a poesia de João Cabral procura sempre alcançar um ideal de lucidez poética, ideal este "que substitua a pura expressão dos estados subjetivos" (NUNES, 2007, p. 28). Ou seja, deve haver no fazer poético um controle racional no sentido de evitar que o acaso, favorecido pela inspiração, tome 
conta dos versos e os contamine com fenômenos subjetivos como a efusão sentimental, o excessivo fluxo de ideias e até mesmo o fascínio de um sonho.

Para Nunes, depois de vencida essa briga com o fluxo de sentimentos interiores, o poeta pode, enfim, construir o seu poema como se fosse uma máquina de linguagem. Após atingir esse "estado de indiferença dispersiva e repousante" (VALÉRY apud NUNES, 2007, p. 29) o poeta pode trabalhar os seus versos de uma maneira mais lúcida e objetiva. A poesia de João Cabral realiza esse procedimento de maneira a fazer com que o verso seja para ele um "organismo que vive dos germes mortos da experiência subjetiva" (NUNES, 2007, p. 29). Dessa forma, a experiência interior pela qual o poeta passa precisa morrer para poder renascer na linguagem; ou seja, o sentimento, fruto dessa experiência interior, deve ser deixado de lado para poder surgir como verso (linguagem) no papel.

"O Poema", do livro O Engenheiro, faz essa alusão aos germes mortos que restam quando um poema é escrito. Nele, o eu poético se pergunta a respeito dos monstros que habitam o papel e de que maneira eles podem surgir a partir da matéria morta que, para esse "eu", representa as palavras de um poema:

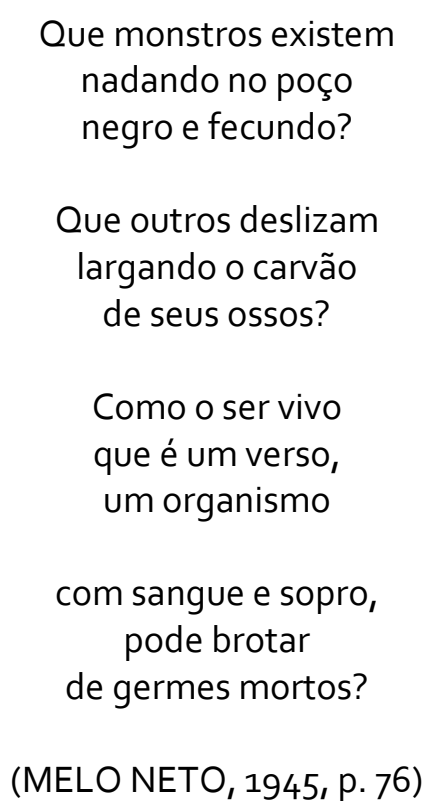

Para explicar de que maneira o poema brota desses germes mortos, Nunes usa o termo "dupla calcinação"; primeiro na passagem da experiência interior que se faz 
em verso, e a segunda do próprio verso que "sendo vivo se mineraliza na matéria física da folha em branco, na qual o verso irrompe.". No poema "O Engenheiro", de livro homônimo, o "eu" fala de um mundo justo e exato, pensado por um engenheiro:

$$
\begin{aligned}
& \text { O lápis, o esquadro, o papel; } \\
& \text { o desenho, o projeto, o número: } \\
& \text { o engenheiro pensa o mundo justo, } \\
& \text { mundo que nenhum véu encobre. }
\end{aligned}
$$

(MELO NETO, 1945, p. 69)

O mundo desse engenheiro será destituído dessa subjetividade (véu) que encobre o seu trabalho. Ao eliminar o sentimento, o poeta-engenheiro pode trabalhar livremente com "a fria natureza da palavra escrita" (Psicologia da Composição, VII, 1947) e buscar, sem empecilhos, a lucidez poética. Para completar essa ideia de contenção nos sentimentos na poesia de João Cabral, coloco abaixo uma das estrofes do poema "A Lição de Poesia" ainda do livro O Engenheiro, em que as palavras sujam o papel com o seu "carvão da emoção extinta":

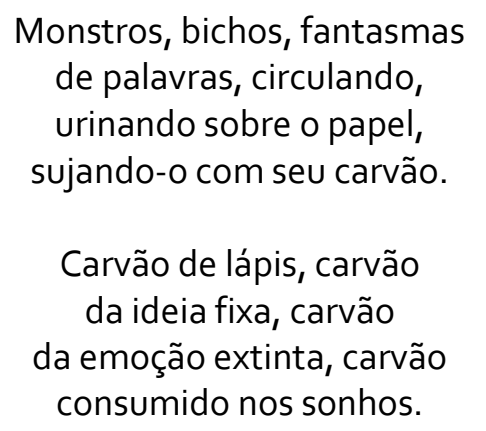

(MELO NETO, 1945, p. 78)

\section{Eucanaã Ferraz}

A poesia de Eucanaã Ferraz possui muita semelhança com a de João Cabral em vários aspectos, entre eles a questão da visualidade através da busca pelas imagens dentro de um poema e o exercício com a linguagem no sentido de procurar trabalhar os versos removendo possíveis excessos. Mas, embora tenhamos esses pontos de contato entre os dois poetas, em Eucanaã Ferraz há uma diferença fundamental que 
foi possível apontar ao longo da leitura de sua obra: a experiência interior subjetiva, proposta por Benedito Nunes, que em João Cabral torna-se matéria residual e morta, permanece, às vezes de forma contundente, na poesia de Eucanaã Ferraz.

Enquanto que no poeta pernambucano a experiência interior é deixada de lado para dar lugar à matéria de linguagem, em Eucanaã foi possível perceber que, embora haja uma tentativa de deixar esses sentimentos fora do papel, o "eu lírico" acaba se expressando de maneira a parecer um sujeito contemplativo que vê não apenas o claro da poesia, como acontece em João Cabral, mas também o escuro, entendido aqui como a experiência interior.

Em outras palavras, Cabral se atentou em manter a sua poesia em estado de linguagem, deixando de fora aquilo que considerava irrelevante para o trabalho poético. Nesse sentido sua poesia é clara por querer

(...) dominar as regras de construção de seu poema e poder construílo de tal modo que a obra não seja, pela sua ressonância puramente evocativa, uma réplica da fecunda desordem dos estados interiores, fadada a restaurar na linguagem a transitoriedade da emoção originária, mas sim uma coisa sólida e ordenada. (NUNES, 2007, p. 30)

Como foi dito acima, há na poesia de Eucanaã esse claro de João Cabral mas também um lado escuro, fruto da sua experiência interior. Essa escuridão pode ser entendida como um lado mais íntimo e abstrato da sua poesia, aspectos estes que culminam com uma maior contemplação dos próprios sentimentos interiores; usando das palavras de Célia Pedrosa no seu texto Poéticas do Olhar na Contemporaneidade: "(...) o visível na poesia de Eucanaã acaba então sendo lugar habitado pelo abstrato, vago e erradio." (PEDROSA, 2005, p. 90). Ou seja, existe a claridade das imagens, visíveis para o leitor da sua poesia, mas há também o invisível, o lado em que o "eu" vivencia internamente aquilo que sente. Para exemplificar melhor esse lado sentimental da poesia de Eucanaã, consideremos alguns exemplos desse uso para mostrar o contraste entre a maneira de expressão dos dois poetas. 
No livro Martelo, seu segundo livro de poemas, há uma tendência desse "eu" poético de contemplar algo e, a partir dessa experiência subjetiva, tentar manter esse sentimento ao convertê-lo em matéria de linguagem. No poema "Fugace" isso fica claro quando o sujeito lírico, ao olhar prédios e edifícios, deseja ver insinuar-se algo de vivo em meio a tudo:

\author{
Os dias fossem isso: \\ gastar os olhos a fio \\ em pesquisar os claros \\ de entre carros e edifícios \\ e, nisto, ver insinuar-se \\ na brecha \\ uma coisa viva, \\ na cidade resto, \\ cidade morto.
}

(FERRAZ, 1997, p. 36)

O interessante desse poema é que essa "coisa viva" a qual ele se refere pode ser justamente essa experiência interior, essa vontade de sentir algo em meio a uma cidade de carros e edifícios; e o verso final enfatiza essa visão negativa daquilo que o "eu" poético olha: uma cidade morta. A poesia para esse sujeito lírico não é apenas construção e engenharia, é também aquilo que experimentamos de belo em meio ao caos de uma cidade, e essa experimentação interior é o que o "eu" deseja pesquisar e transpor para o verso.

Ainda no mesmo livro, e logo após "Fugace", temos o breve poema "Forma". Nele, o sujeito lírico expõe o que é preciso para que um poema tome forma; e não são apenas palavras que esse "eu" deseja nele, mas sentimentos:

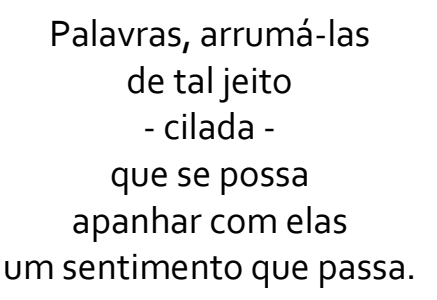

(FERRAZ, 1997, p. 38) 
O poema para esse sujeito é a junção palavra-sentimento; é essa a "forma" que o poema deve ter e é disso que ele é constituído. É importante notar que são as palavras que realizam essa junção, e não o sentimento; a experiência interior passa por essa "cilada" criada pelas palavras e é organizada por ela. A diferença com João Cabral é que essa experiência subjetiva passa, além do crivo das palavras, por uma calcinação que a deixa apenas um resíduo morto, como aponta Benedito Nunes.

Outro ponto interessante de se observar nesse poema é que, embora o sentimento seja importante para um poema, a sua forma também é; prova disso está no formato de " $X$ " que o poema possui, podendo simbolizar essa exatidão com que se trabalha com a palavra. Esse é um aspecto interessante para se compreender a obra de Eucanaã: seu cuidado com a transposição da experiência interior para o poema é proporcional à cautela com que se organizam os versos.

No poema "Dor" do livro Rua do Mundo, o sentimento de dor, fruto de um amor desfeito, permanece nesse "eu" de maneira a cintilar no ferimento causado pelo rompimento amoroso:

\author{
Amor desfeito. \\ Do vento mais suave \\ (...) \\ o movimento mínimo \\ fere nosso rosto \\ e o silêncio semelha o dente de um ácido \\ sombrio sobre o ferimento, \\ ainda tão recente, \\ cintilante.
}

(FERRAZ, 2004, p. 89)

Toda essa temática por si só já demonstra um certo platonismo no sentimento amoroso e na dor causada depois que esse amor acaba; esse sujeito lírico é romântico e apaixonado, e faz com que o sentimento de desilusão não permaneça apenas no "eu", mas também nas palavras que capturaram essa experiência interior e as mantiveram ao longo dos versos. Além disso, a sucessão de imagens que se 
desdobram a partir "do vento mais suave", reforça o caráter plástico da poesia de Eucanaã.

Ainda na temática do amor, o poema "Água-forte", do livro Cinemateca, mantém essa imagem platônica e vai mais longe ao desejar viver no engano do amor, e considerar aquilo que sente uma "triste alegria":

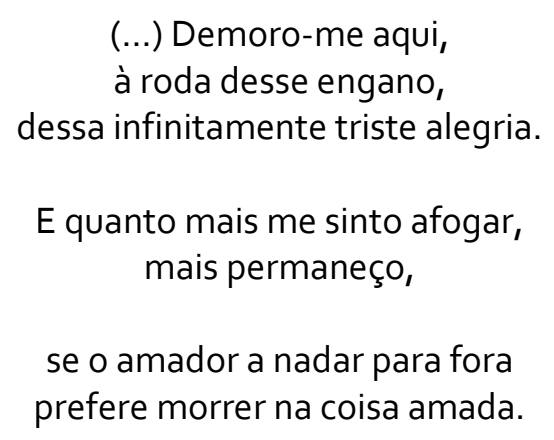

(FERRAZ, 2008, p. 104)

O sujeito poético deseja permanecer próximo da pessoa amada mesmo sabendo que irá se afogar. Essa ideia de ver alegria na tristeza e de desejar "morrer na coisa amada" é claramente romântica e remete inclusive aos versos de Camões no soneto "Transforma-se o amador na cousa amada", reforçando assim o caráter sentimental da poesia de Eucanaã.

No poema "Manifesto", o sujeito lírico expõe alguns desejos daquilo que considera importante para se viver melhor. Além de exaltar o "prazer sem custo" e querer "dividir o bom que venha feito o sol, gratuito." O "eu" denuncia uma vontade de viver o espontâneo, aquilo que vem sem planejamento ou algum tipo de cálculo:

\footnotetext{
Quem sabe se o dom, o sem-razão e o sem motivos possam mais do que exigimos
}

Em seguida, esse sujeito lírico arremata com uma exaltação ao coração, desejando que ele se exiba perante a todos sem qualquer tipo de medida ou controle emocional: 


$$
\begin{gathered}
\text { (...) para } \\
\text { que o fogo nunca esteja frio } \\
\text { e o coração passeie seus cavalos. }
\end{gathered}
$$

(FERRAZ, 2008, p. 71)

Esse fogo deve permanecer quente e o coração precisa passear diante de todos. Ou seja, é a partir desse fogo que o sentimento e a emoção de um momento podem aparecer, seja na poesia, seja na vida de uma pessoa. O manifesto desse "eu" poético é de ver um mundo em que as coisas sejam feitas sem pensar, e que o "semrazão e o sem motivos possam mais do que exigimos.", sem qualquer tipo de filtro ou controle emocional. É claro que a poesia de Eucanaã Ferraz não é uma corrente de emoções, despejadas no papel sem qualquer tipo de organização na linguagem; mas nesse poema manifesto, o "eu" revela um viver dessa forma, viver este que possa ser refletido em atos mais espontâneos e calorosos.

No seu poema seguinte, "Sumário", o sujeito lírico parece explicar melhor o que é esse mundo que ele deseja. Como foi dito acima, a poesia de Eucanaã, embora transmita sentimentos que sobrevivem à experiência interior, é no mundo e na convivência humana que devemos passear os cavalos do coração:

$$
\begin{aligned}
& \text { O poema ensina a estar de pé. } \\
& \text { Fincado no chão, na rua, o verso } \\
& \text { não voa, não paira, não levita. }
\end{aligned}
$$

(FERRAZ, 2008, p. 73)

Ao escrever os versos, o poeta deseja se levantar e sair de um estado de imanência ao qual está submetido. Mas, ao se levantar, o poema não pode estar fincado na rua, ele deve voar e sair da condição de linguagem para transmitir algo: um sentimento, emoção, experiência, etc. Nossas vidas devem ser guiadas pelo "sem razão e os sem motivos" e devemos "dividir o bom que venha feito sol", como o poema "Manifesto" nos diz; mas, antes de voar, temos que nos levantar, e é isso que o poema nos ensina. 
Mas é no seu livro mais recente, Sentimental, publicado em 2012, que esse eupoético será, como o próprio título do livro diz, sentimental. Já no poema de abertura, intitulado "O Coração", há um prenúncio do que está por vir ao longo do livro:

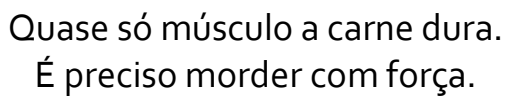

Esses dois versos iniciam uma verdadeira corrente de sentimentos que estarão presentes na maioria dos poemas do livro; fica a sensação de que, após a mordida no coração, tudo aquilo que estava interiorizado nele sai em um fluxo contínuo de emoções.

O que fica mais claro, depois de uma primeiro leitura do livro, é a não economia de palavras na hora de escrever: os versos são longos e diferentes daquilo que esse "eu" poético desejou no seus livros anteriores, especialmente Desassombro e Martelo. Neste, o poema é tratado como uma pedra a ser lapidada, e as palavras passavam pelo crivo do martelo que esse sujeito lírico carregava. Em Sentimental isso acontece muito pouco; os poemas são, na sua maioria, de versos longos, quase que uma narrativa. Mesmo aqueles que apresentam uma construção formal mais "lapidada" possuem uma exteriorização dos sentimentos desse sujeito lírico.

No poema "Uma Gaivota Viesse", é possível perceber que o sujeito lírico não economiza nas palavras quando mostra sua tristeza com relação a "o que nos parte / o que nos corta", como diz no final do poema:

O amigo, em Lisboa, pergunta o que quero de Lisboa; nada, respondo, não quero senão o que não vem nos postais mais um ou dois postais de lugares onde nunca fui feliz e ainda assim, agora e sempre, eu quis, não quero, Alberto, de Lisboa, senão o que ela não dá, o que ela guarda e é preciso roubar, a secreta alegria que não cabe nos guias de turismo,

\section{(...)}

de nada valem os antiquários; quando voltamos de Lisboa, tudo o que trazemos, percebemos, está partido, por isso, Alberto, não vale a pena trazer nada, que daí só trazemos, sem dar conta, 
o que nos parte,

o que nos corta,

mal fechamos a mala, mal abrimos a porta.

(FERRAZ, 2012, p. 15)

Com versos mais longos que o habitual na sua obra poética, o eu lírico desse poema (e de todo o livro) é alguém que expressa seus sentimentos de maneira mais aberta e direta, sem se preocupar em "escrever curto - no corte", como disse no livro Martelo, 15 anos antes. Essa mudança no tratamento com a palavra é muito clara ao longo da sua obra, e pode configurar uma tendência desse sujeito poético de deixar de lado o poema lapidado, seguindo para uma tendência mais ligada à expressão subjetiva livre, sem a preocupação, até certo ponto, com aspectos formais.

Ainda no livro Sentimental, o poema "Da Vista e do visto" revela quase que uma conversa desse "eu" com o seu leitor. Ao longo das duas estrofes, esse sujeito lírico relembra algo que o entristece e que não o abandona:

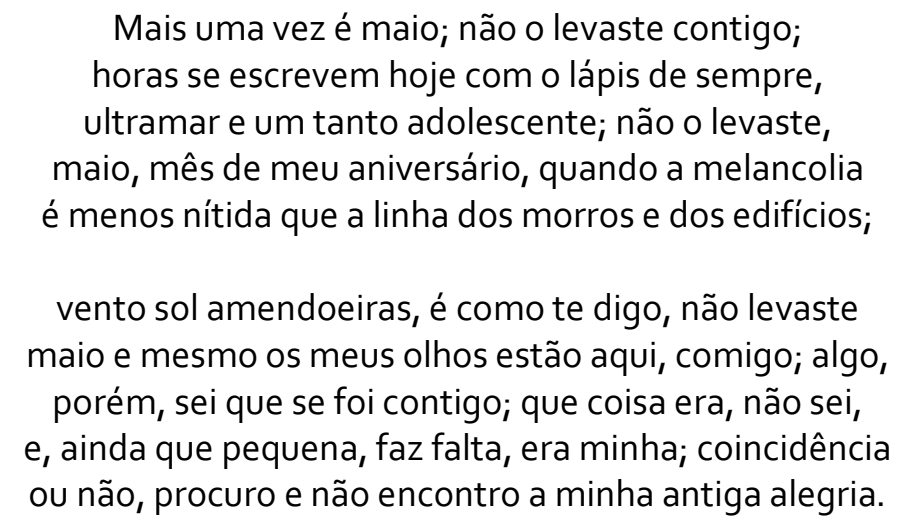

(FERRAZ, 2012, p. 24)

Esse poema é um ótimo exemplo do quanto o sujeito poético revela aquilo que sente como se fosse "um tanto adolescente", como diz no terceiro verso. Além disso, a alusão de que maio é o mês do seu aniversário demonstra uma aproximação desse "eu" com o seu leitor, deixando a poesia mais pessoal. Esse tom mais confessional e melancólico é marcante ao longo de todo o livro; inclusive, o poema seguinte, intitulado "Melancolia", funciona como uma continuação desse estado em que o 
sujeito lírico se encontra. Não é necessário transcrevê-lo aqui, apenas faço esse apontamento para reforçar a questão do sentimental que permeia todo o livro.

O poema "Sob a Luz Feroz do Teu Rosto", é que que melhor expõe esse apreço pelos sentimentos dentro de um poema; no caso, o eu-poético descreve o amor que tem por um leão, que pode ser entendido aqui como a expressão de sentimentos interiores:

Amar um leão usa-se pouco, porque não pode afagá-lo o nosso desejo de afagá-lo,

Para esse "eu", é difícil afagar um animal como o leão mesmo desejando isso, e ter qualquer contato direto com ele deve ser extremamente raro. Em seguida, e em uma alusão à "Fábula de Anfion" de João Cabral de Melo Neto, em que Anfion joga a flauta no mar, o "eu" poético reforça o fato de não podermos amar um leão agora que "a flauta que tudo encantaria" foi quebrada:

Amar um leão não se devia, agora que já não somos divinos, quando a flauta que tudo

encantaria, gentes animais pedras, nós a quebramos contra a ventania; amar

um leão é só distância: tê-lo ao seu lado, não poder beijá-lo, o deserto que habita em torno dele;

Para esse sujeito lírico, amar um leão é só à distância; não podemos nos aproximar e explorar tudo aquilo que ele pode oferecer. Por isso, para evitar de sermos atacados por essa criatura imprevisível, é melhor amar os objetos à nossa volta; esses objetos são seguros, inofensivos, e não corremos o risco de cairmos em uma armadilha:

era mais certo amar um barco, era mais fácil amar um cavalo; 
amar um leão é não poder amá-lo;

Esse amor ao leão toma proporções românticas quando o eu-poético deseja que esse animal o mate, e vai mais além ao assumir que está seria "a dor maior, mais que esperada":

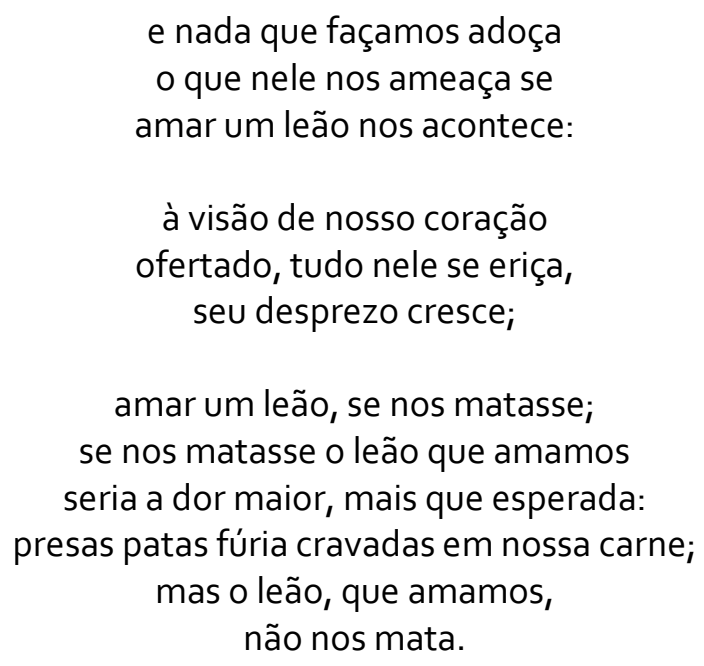

Esse ideal, nitidamente romântico, de morrermos pela dor maior, mostra que o sujeito lírico não só deseja esse leão para si, como quer morrer com as patas desse animal cravadas na própria carne.

"Sob a Luz feroz do Teu Rosto" pode ser considerado um poema símbolo dessa maneira que o eu-poético em Eucanaã Ferraz se expressa: há um desejo de manter a experiência interior viva quando passada para as linhas do poema, e esse leão representa justamente essas emoções interiores que temos medo de expor por corrermos o risco de cairmos em um ideal romântico e sentimental.

\section{Considerações Finais}

Podemos atestar uma certa tendência do sujeito poético de Eucanaã Ferraz de colocar sentimentos ao longo dos seus versos, contrariando uma corrente que, desde a Semana Moderna de 22, vem mantendo essa questão do sentimental e romântico como algo a ser suprimido nos versos de um poema. 
O Modernismo foi um movimento que procurou renovar a produção artística e cultural da época ao propor um novo olhar para a arte; na poesia, houve um movimento a favor de uma estética e temática menos rebuscada e mais voltada para o comum e mundano da nossa sociedade, diferenciando-se assim da estética romântica, mais idealista, individualista e distante do contexto social da época.

Eucanaã Ferraz parece querer transmitir, através da sua poesia, conceitos e ideais românticos; isso não significa dizer que a sua poesia é romântica, ou que tende a se expressar da mesma maneira que os poetas daquele período, mas que de alguma forma a sua poesia defende certos valores e visão de mundo que se adequam ao ideal romântico.

\section{Referências Bibliográficas:}

FERRAZ, Eucanaã. Livro Primeiro. Rio de Janeiro: CIP-BRASIL, 1990. . Martelo. Rio de Janeiro: Ed. Sette Letras, 1997. . Desassombro. Rio de Janeiro: Ed. 7 Letras, 2002. Rua do Mundo. São Paulo: Companhia das Letras, 2004. . Cinemateca. São Paulo: Companhia das Letras, 2008. Sentimental. São Paulo: Companhia das Letras, 2012.

MELO NETO, João Cabral de. Obra Completa. Rio de Janeiro: Ed. Nova Aguilar. 2003.

NUNES, Benedito. João Cabral: A Máquina do Poema. Org. Adalberto Müller. Brasília: Ed. UNB, 2007.

PEDROSA, Célia. Poéticas do Olhar na Contemporaneidade. São Paulo, n. 8, p. 83-103, 2005.

${ }^{1}$ João Felipe Gremski é atual mestrando do Programa de Pós-Graduação de Letras da Universidade Federal do Paraná (UFPR) em Estudos Literários.

Email: gremski@msn.com 